\title{
Acquisition of French Polysemous Vocabularies: Schema-based Instruction versus Translation- based Instruction
}

\author{
EBRAHIM KHODADADY \\ Ferdowsi University of Mashhad, Iran \\ M. Saber Khaghaninizhad \\ Department of English Language and Literature, Shiraz University, Iran
}

Received: 10 November 2010 / Accepted: 18 January 2011

ISSN: $1697-7467$

\begin{abstract}
This study attempted the effectiveness of two types of vocabulary instruction (i.e. schema-based instruction (SBI) and translation-based instruction (TBI) on the acquisition of second language words. Inspired by intact group design, fourtynine intermediate Iranian learners of French were divided into three groups; two experimental groups (SBI and TBI) and a control group. The experimental groups were given 30 minutes of instruction on the target words, namely the verb arriver and the preposition sur. In order to examine the effectiveness of the focused instructions, an acceptability judgment test and a production test were administered prior to instruction as the pre-tests, two days after the instruction the first post-test and two weeks after the instruction the second post-test were given. The results showed that SBI tended to be as effective as TBI for acceptability judgment test and drastically more influential for production test. This study suggests that schema-based techniques derived from cognitive semantics can serve as an extremely promising pedagogical devise in teaching L2 vocabularies.
\end{abstract}

Keywords: Schema-based vocabulary instruction (SBI), translation-based vocabulary instruction (TBI), acceptability judgment test, production test

Adquisición de vocabulario polisémico francés: instrucción basada en esquemas frente a instrucción basada en la traducción

RESUMEN: Este estudio intentó demostrar la eficacia de dos tipos de enseñanza de vocabulario (es decir, la instrucción basada en esquemas (IBE), basada en la traducción (IBT) de la adquisición de las palabras en la segunda lengua. Inspirado en el diseño del grupo intacto, cuarenta y nueve alumnos iraníes de nivel intermedio de francés se dividieron en tres grupos; dos grupos experimentales (IBE y IBT) y un grupo control. A los grupos experimentales se les dieron 30 minutos de instrucción sobre las palabras meta, a saber, el verbo arriver y la preposición sur. A fin de examinar la eficacia de las distintas formas de instrucción desarrolladas, se administraron, una prueba de juicio para la aceptabilidad y también una prueba de producción a la instrucción; los posttests se administraron dos días después de la instrucción y dos semanas después de la instrucción el segundo. Los resultados mostraron que IBE tendían a ser tan eficaz como LCT para la prueba de aceptabilidad y drásticamente más influyente para la prueba de 
producción. Este estudio sugiere que las técnicas basadas en esquemas derivados de la semántica cognitiva pueden considerarse como un recurso pedagógico muy prometedor en la enseñanza de vocabularios en la L2.

Palabras clave: Enseñanza de vocabulario basada en esquemas (OSE), enseñanza de vocabulario basada en la traducción (TBI), prueba de aceptabilidad, pruebas de producción

\section{INTRODUCTION}

Intuitively, more frequent words may seem easier to learn and teach than less frequent words because of their 'vitalness' (Howards, 1964). On the contrary, however, high-frequency words have been regarded as a notorious obstacle for learners (Bensoussan and Laufer, 1984; Curtis, 1987; Laufer, 1997). The source of difficulty arises from the very nature of their frequency, that is, the more frequently a given word is used, the more polysemous it tends to be (Howards, 1964). It is thus highly likely that when learning high-frequency words, learners will encounter a large number of polysemous words that is words which have multiple semantically related senses (Lyons, 1977). Because of the polysemous nature, it is often difficult for learners to intuitively understand how seemingly chaotic senses are semantically related (Tyler and Evans, 2004). For example, when encountering the various senses of the English preposition on, such as 'The book is on the desk', 'They are on a campaign to stop war' or 'Japanese live on rice', it is highly likely that learners cannot see how each sense of on is semantically related to the others.

A polysemy is a word or phrase with multiple, related meanings. A word is judged to be polysemous if it has two senses of the word whose meanings are related. Since the vague concept of relatedness is the test for polysemy, judgments of polysemy can be very difficult to make. Because applying pre-existing words to new situations is a natural process of language change, looking at words' etymology is helpful in determining polysemy but not the only solution; as words become lost in etymology, what once was a useful distinction of meaning may no longer be so. Polysemy comes from Neo-Latin polysemia, which comes from Greek polusemous [poly- (many) + sema (sign)] giving us a linguistic term, «having many meanings» or multiple meanings. We also have polyseme (singular) [puh LIS uh mee], and polysemes (plural) [puh LIS uh meez]. The words polysemy [puh LIS uh mee or PAWL i see» mee] and polysemous [puh LIS uh muhs or pawl» ee SEE muhs] are defined as «having or characterized by many meanings; the existence of several meanings for a single word or phrase».

There are several tests for polysemy, but one of them is zeugma (Laufer, 1997); if one word seems to exhibit zeugma when applied in different contexts, it is likely that the contexts bring out different polysemys of the same word. If the two senses of the same word do not seem to fit, yet seem related, then it is likely that they are polysemous. The fact that this test again depends on speakers' judgments about relatedness, however, means that this test for polysemy is not infallible, but is rather merely a helpful conceptual aid. To make matters worse, polysemous words are difficult not only for elementary- and intermediate learners but also for advanced learners as well. Lennon (1996) demonstrated 
that even advanced language learners showed frequent erroneous use of high-frequency words such as go, put and take in their speech. He argued that 'advanced learners require detailed classroom vocabulary work on "simple" high-frequency verbs, which explores meaning-range and limitation, collocational possibilities and restrictions, sense relations such as partial synonymy within lexical sub-systems (1996: 35)'.

Given the importance of learning high-frequency words and the learning difficulties this may entail, it is important to consider how attention can be paid to polysemous words in L2 vocabulary teaching and learning. As Curtis (1987: 49) argued, 'because most highfrequency words have multiple meanings, instruction should be designed so that it focuses on the word meanings which students need to learn'. The problem here is how to lessen the learning burden of such words. In other words, how can teachers facilitate learners' realization of the meaning potential of a given polysemous word? Morimoto and Loewen (2007) wrote:

Despite their importance, it seems that polysemous words have not been a target of systematic enquiry in the field of second language acquisition and teaching. There are a number of possible reasons for this relative lack of attention. First, there seems to be a tacit assumption that learners can learn various senses of a given polysemous word implicitly without being intentionally taught (348-51).

In terms of instruction, it is virtually impossible for teachers to treat every single sense of a word within a limited time (Nagy, 1997). Most importantly, it is conceivable that the paucity of interest in teaching polysemous words can be attributed to the lack of a theoretical framework within which to systematically view polysemy. It goes without saying that the way teachers view polysemy plays a crucial role in teaching. In better words, if teachers have a sound theoretical understanding of how different senses are semantically related, their teaching could be more systematic and facilitate learners' acquisition.

As Morimoto and Loewen (2007) noted, there are two major approaches to polysemy, the lexical network approach (Lakoff, 1987; Taylor, 1988; Tyler and Evans, 2001, 2004) and the core-schema approach (Dewell, 1994). In the lexical network approach, various senses of a given polysemous word are seen to form a network, or 'radial category' (Lakoff, 1987), in which metaphorical senses are derived from the central prototype. The core-schema approach, on the other hand, suggests that the various senses can be derived from a single core schema which serves as a base from which different senses derive as a result of cognitive operations such as focalization, vantage point shift (Langacker, 1987) and image-schema transformations (Gibbs and Colston, 1995; Lakoff, 1987). The present paper will limit its discussion to the core-schema approach and its possible positive influence on vocabulary expansion. Although schema has been a vital tool in the semantic analyses of polysemy on a theoretical basis, the issue as to whether it can serve as a pedagogical device remains to be empirically investigated. This study is one of the first attempts to establish a link between additional language vocabulary teaching and cognitive semantic theory by proposing an instruction called schema-based instruction (SBI). In order to explore the potential effectiveness of SBI, this study addressed the following research questions. 
* Is there a meaningful difference between the performance of SBI (schema-based instruction) learners and those of the control group?

* Is there a difference between SBI (schema-based instruction) and TBI (translation based instruction), as measured by learners' performance on a vocabulary acceptability judgment test?

* Is there a difference between SBI and TBI, as measured by learners' performance on a vocabulary production test?

\section{LiterATURE REVIEW}

Polysemy has been one of the central research agendas in the field of cognitive semantics. The basic tenet of cognitive semantics is that various senses of a given polysemous word are neither arbitrary nor idiosyncratic, but instead systematic and semantically motivated (Lakkoff, 1987; Taylor, 1988). There have been multiple lines of research that have sought to investigate the intra-lexical structures of polysemous words such as over (Dewell, 1994; Lakoff, 1987; Tyler and Evans, 2001, 2004), in, on (Beitel et al., 1997; Goddard, 2002) and through (Hilferty, 1999). One of the key concepts in such analyses is image-schema (Johnson, 1987; Lakoff and Johnson, 1980; Lakoff, 1987), which can be defined as the schematic structures which are generated through our perceptual interactions and bodily movements in our physical environment that 'make it possible for us to experience, understand, and reason about our world' (Johnson, 1987: 19). Making use of schema, researchers in cognitive semantics have sought to visualize the sense network of various polysemous words (Brugman, 1988; Dewell, 1994; Lakoff, 1987).

\subsection{Sechema-based approach to "arriver"}

When Iranian learners of French try to learn 'arriver', they tend to associate it with the Persian equivalent residan forming an 'arriver=residan equation. The problem is that these two terms are not perfectly synonymous because of cross-cultural differences arriver can be used in some communicative situations in French which do not match with Iranian semantic expectations about the usage of this verb. Thus based on what learner has found it cannot be used in the case of 'happening of something'. In the second place, the difficulty also arises from the fact that arriver can be used metaphorically in abstract domains such as 'accomplish a work successfully', and this is where interlingual differences become larger. 


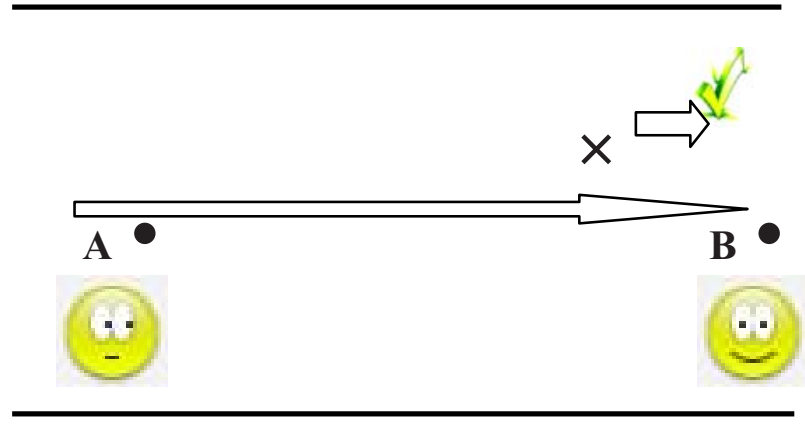

Figure 1. Schema for arriver.
A) J'ai arrive' a' Paris a' $8 \mathrm{~h}$.
(I arrived in Paris at 8.)
B) Il a arrive' a' faire son examen.
(He succeeded in doing his test.)
C) Il arrive qu'il successe'.
(He happens to be successful.)
D) Madline est une arriviste.
(Madline is a go-getter.)

Considering the learning difficulties explained so far, the central issue to be considered is how to assist learners in overcoming the cross-linguistic learning difficulties and enable them to realize the meaning potential of arriver. One way to cope with this situation is to adopt a core-schema approach and assume that there is a common meaning thread underlying all senses of arriver, which can be stated as 'moving from point A to point B and do or make something happen successfully'. The image-schema of arriver can be represented as Figure 1. By assuming the underlying core meaning of 'arriver' as discussed above, one may be able to understand intuitively how seemingly chaotic senses of a given polysemous word are semantically related to one another (Lindstromberg, 1996).

\subsection{Schema-based approach to "sur"}

Now let us see how this model can account for the various uses of sur, as shown in sentences (1) to (4), by using the image schema shown in Figure 2.
A) Mettez le livre sur la table.
(Put the book on the table.)
B) Il va sur Paris.
(He goes toward Paris.)
C) Ell' en cherche sur son ordinateur.
(She searches for it through his computer.)
D) Votre nombre est 7 sur 10 .
(Your mark is 7 out of 10.)
E) Vous pouvez etre ici sur votre droite. (Based on your right you can be here.) 


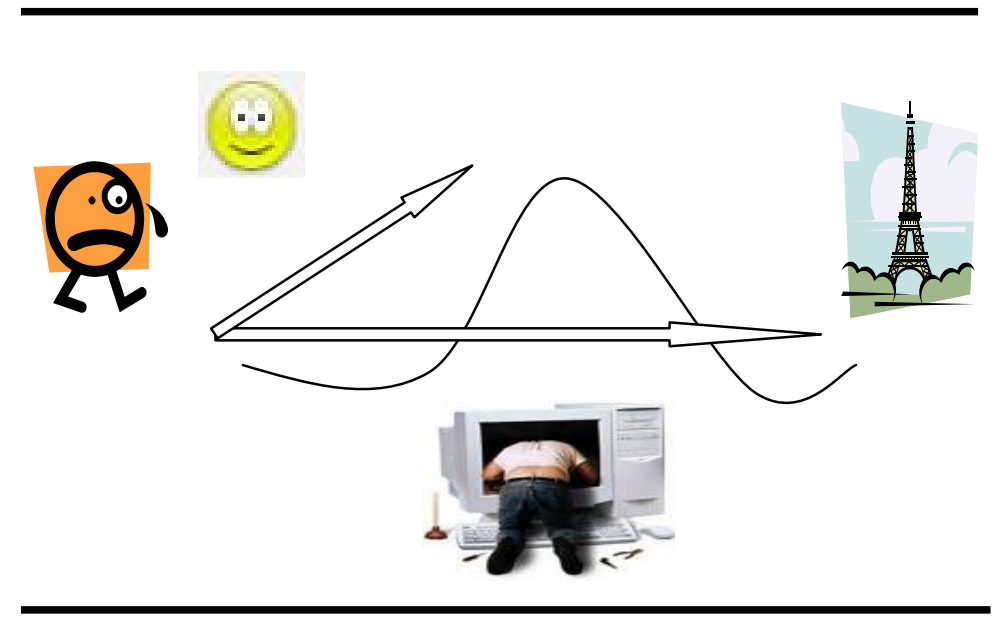

Figure 2. Schema of sur.

There are potentially four areas to be focalized in the image-schema for sur. In sentence (A), (D) and (E) the upward part of the curve is given focal prominence, the spatial relationship between two objects is similar to the use of above or on in English. In sentences (B) and (C) 'sur' represents a kind of movement in a particular direction toward an aim (for example movement from point A to point B). Again inspired by schemabased approach, all related meanings of sur as a French preposition can be summarized as 'to be on or toward something' which is represented in figure 2.

\subsection{Schema-based instruction}

According to Morimoto and Loewen (2007) 'schema-based instruction (SBI) can be defined as a form of vocabulary instruction in which the process of learning a word is mediated by the use of schema'. The aim of SBI is not to teach various senses of a given word exhaustively but to provide learners with a basis on which they can effectively process the various meanings in subsequent input. The assumption here is that if learners have an understanding of the underlying common meaning (core meaning) of a given word (Bolinger, 1965), it can serve as a basis for comprehending novel usages (Tyler and Evans, 2004). There are four advantages in SBI. The first is concerned with the efficiency, or cost-benefit aspect, of vocabulary acquisition (Nation, 2001). As Hatch (1978) pointed out, second language learners are engaged in the continual processes of 'data-gathering' and 'rule-forming', which is in parallel to what Henriksen (1999) called 'item learning' and 'system changing'. In learning a word, learners encounter words in a contextualized manner. For example, given the sentences J'ai arrive' a' Paris a' 8 h learners may form a rule that the verb arriver can be used only when there is a movement from one place to another. As learning proceeds, learners are likely to encounter more usages such as Il arrive qu'il successe'and Il a arrive' a' faire son examen, which further modify the existing hypotheses. At this point, some learners may extract the common underlying 
meaning of arriver which is independent of the context. In this regard, lexical acquisition can be seen as a process of 'decontextualization' (Bolinger, 1965; Curtis, 1987). However, while such a process might occur efficiently in an French as a Foreign Language environment, where learners' mental representation of a word can be biased, depending on the nature and the amount of input they get, which leads to either 'over-generalization' or 'undergeneralization' of the meaning (Taylor, 1985). Therefore, instead of providing learners with various senses in a piecemeal fashion, the presentation of image-schema seems to be more efficient and cost-beneficial.

The second advantage of SBI is that because of its image-schematic nature, the use of image-schema can enable learners to understand intuitively how the intra-lexical structure of a given word is organized, especially how metaphorical senses are derived from a prototype. As Csábi (2004:236) argued, 'if language learners acquire the motivations of the senses of polysemous words and of the idioms in which they appear, they will learn, remember, and use them more easily'.

The third advantage of SBI is that it does not make learners rely exclusively on first language (L1) equivalents in learning a word. It has been reported that learners often make use of their L1 as an anchoring device for learning L2 words, which is what Melka, (1997) called 'search-translation-equivalent (STE) strategy'. For instance, when Iranian learners of French learn the verb arriver, they often equate it with the Persian equivalent residan. However, as has been shown, the knowledge of residan cannot be directly transferred to arriver, for the semantic ranges of the two are not identical. As shown in Figure 3, the use of image-schema, which is language-neutral in nature, could instead enable learners to understand the L2 word without being constrained by its L1 equivalent. Finally, SBI involves learners in 'deep processing' of the words (Craik and Lockhart, 1972). Proponents of the 'depth of processing' hypothesis claim that the more cognitive effort invested into word learning, the more likely those words will be remembered in both the short- and long-term. In principle, ISBI involves deeper processing of words than does translation-based instruction, for learners are given opportunities to process various senses of the target words and asked to consciously reflect on their core meaning.

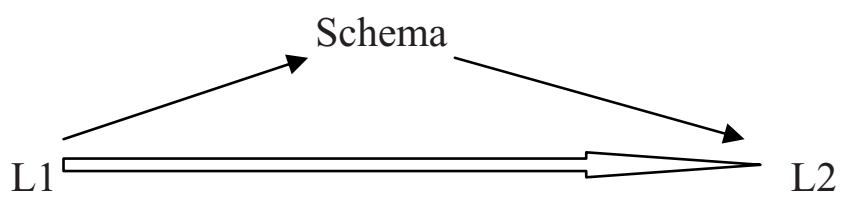

Figure 3. Relationship between L1, L2 and schema.

\section{Method}

\subsection{Subjects}

The participants in this study came from three intact classes, and consisted of 49 Iranian learners of French studying in Iran. All of them spoke Persian as their first 
language (L1) and had studied French for at least six semesters at a foreign language institute. The age of the students ranged from 17 to 19 years old and no one had lived overseas before the instruction took place. The participants were divided into three groups. Due to the administrative difficulty in assigning the learners into random groups, the three intact classes were used. Two served as experimental groups, with the first group ( $n_{-}$15) receiving schema-based instruction (SBI) and the second group ( $\left.\mathrm{n}_{-} 16\right)$ receiving translation-based instruction (TBI). The remaining third group served as a control (n _ 18) and received no instruction on the target words.

\subsection{Instruction types}

The present section describes the SBI and TBI instructional details. The aims of these instructions were to raise learners' awareness about the cross-linguistic semantic differences between L1 and L2 polysemous words (verbs and prepositions) and to help them realize that vocabulary learning is not simply a matter of one-to-one mapping of L1 onto L2.

3.2.1. Schema-based instruction (SBI) _ The 30-minute SBI instruction was given by one of the researchers in the medium of Persian. There were three phases in SBI. First, the researcher invited learners to come up with a Persian equivalent of arriver and write down 'arriver _ residen' on the board. Having induced an L1 _ L2 equation, the researcher asked the learners to compare three French sentences with the respective Iranian translations and to consider how the meaning of arriver was translated in each sentence. It was assumed that this activity could make learners aware of the limitations of the L1 _ L2 equation, which is what Tomasello and Herron (1989) called the 'garden path' technique. In phase two, the researcher provided the learners with a summary sheet and explained the core meaning of arriver, depicted as an image-schema, and how different senses can be derived from it. In phase three, learners individually worked on translating few French sentences into Persian. Upon completion, a number of students were asked to provide their answers, followed by the researcher's feedback on their appropriateness.

3.2.2. Translation-based instruction (TBI) _ Thirty minutes of TBI was provided by the same researcher in the medium of Persian. Learners completed phase one, which was identical to that in SBI. The purpose of the task was to make learners aware of the limitation of the L1 _ L2 equation. Following the first phase, the researcher explained the semantics of the target word without reference to how various senses of arriver can be derived from the core meaning. In other words, learners were provided with an inventory of meanings associated with the target word as is done in a dictionary. In the next phase (phase three of the SBI lesson plan), learners were asked individually to translate 10 French sentences into Persian. The number of the sentences to be translated in TBI was greater than that in SBI to compensate for the lack of time spent explaining the imageschema. As with the SBI, the researcher asked a few students to share their answers, and gave feedback on their appropriateness. 


\subsection{Materials}

In order to test the effects of the instruction, two vocabulary tests were administered. An acceptability judgment test was used to assess the participants' receptive knowledge of the target words in various contexts. The participants were asked to read French sentences containing the target words and to judge whether the sentences were semantically appropriate or not by circling the answers. The total number of sentences was 30 . Half of the sentences targeted arriver and the other half targeted sur. Due to the limited time available for testing; it was not possible to include distracting test items. For each word, there were 10 sentences in which the target words were used appropriately and five inappropriately. No Persian translations were provided for the sentences and no typographical enhancement was used in the test items. In addition to the acceptability judgment test, a production test was administered to assess participants' productive vocabulary knowledge. Participants were asked to look at a series of pictures provided and to write one French sentence that best described each picture. For each item, the subject noun phrase was provided in a box. Written instructions were given to the participants to use the word(s) in a box for their answers. There were six sentences for each target word, for a total of 12 test items.

\subsection{Procedures}

Prior to the administration of the study, participants were given a short languagelearning background questionnaire. The experimental instruction lessons were taught by one of the researchers, with instruction being giving in Persian; the tests were administered by the classroom teachers. Both instruction and tests took place during regular classroom hours. The overall procedures are summarized in Figure 4. The three testing sessions (pre, post 1 and post 2) were identical, except for a varying order in the presentation of test items. Participants first completed the acceptability judgment test followed by the production test. They were not allowed to consult dictionaries, and on the acceptability judgment test, participants were asked not to go back to the previous questions. The scoring procedures of each test were as follows. In the acceptability judgment test, one point was given for each correct judgment, with a total score of 15 for each word. As for the production test, one point was awarded for each correct answer. However, as the purpose of the test was to assess the use of the target words, any grammatical mistakes were overlooked if the intended meanings were clear.

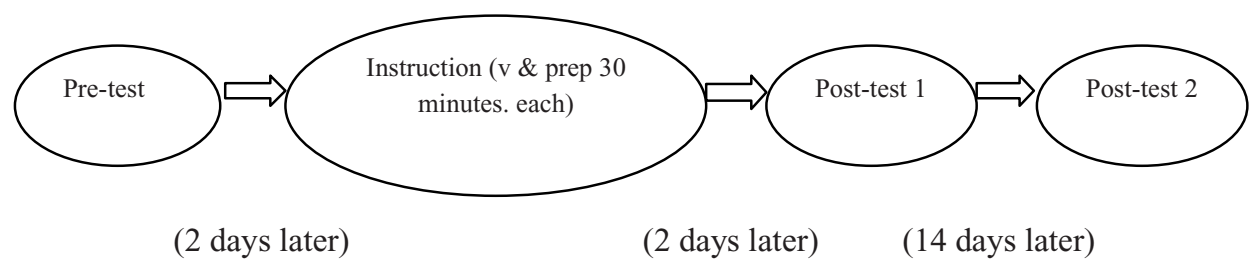

Figure 4. Procedure of the study. 
Descriptive statistics were calculated for the two linguistic items on all tests. In order to compare the relative effectiveness of SBI and TBI on the acquisition of L2 polysemous words, a series of split-plot ANOVAs (SPANOVAs) was performed with the test scores being the dependent variable and type of instruction (SBI, TBI or control) and test time (pre, post 1 or post 2) as the independent variables. The alpha level was set at .05 and a Bonferroni method post hoc pair-wise comparison was conducted on all significant SPANOVAs.

\section{Data Analysis}

\subsection{Acceptability judgment test}

Arriver: Table 1 shows the descriptive statistics of the acceptability judgment test scores for arriver. The accuracy percentages of the test scores are presented in Figure 5. Although all groups showed improvement from pre-test to post-test 1, the gains for the SBI and TBI groups were larger than those of the control group. Additionally, SBI French learners showed a greater degree of betterment than their peers in TBI group.

Table 1. Descriptive statistics of the acceptability judgment test scores (arriver).

\begin{tabular}{|c|c|c|c|c|c|}
\hline & \multicolumn{2}{|c|}{$\operatorname{SBI}(n=15)$} & \multicolumn{2}{|c|}{ TBI $(n=16)$} & Control $(\mathrm{n}=18)$ \\
\hline & Mean \% & $\mathrm{SD}$ & Mean & $\mathrm{SD}$ & Mean $\% \quad$ SD \\
\hline Pre-test & $7.94 \quad 49.09$ & 1.98 & 8.01 & $\begin{array}{ll}53.80 & 1.68\end{array}$ & $\begin{array}{lll}7.92 & 52.65 & 2.21\end{array}$ \\
\hline Post-test 1 & 10.7171 .43 & 1.41 & 9.48 & 66.211 .34 & $\begin{array}{lll}8.03 & 53.90 & 1.75\end{array}$ \\
\hline Post-test 2 & 10.7772 .28 & 1.39 & 9.61 & 67.111 .81 & $8.0654 .01 \quad 1.81$ \\
\hline
\end{tabular}

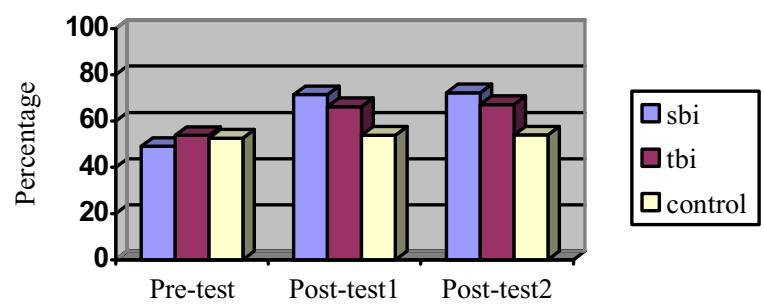

Figure 5. Accuracy percentages of the acceptability judgment test scores (arriver).

Table 2 summarizes the results of the SPANOVA. The main effect for test time was significant (Sig. _. .000); furthermore, the main effect for SBI was also significant (Sig. .000). There was also a significant interaction effect between time and the instruction techniques (Sig._. .05). Post hoc pair-wise comparisons revealed that there were significant 
differences in post-test 1 scores among the three groups. As for post-test 2, there was a significant difference in the scores between TBI group and the control group while a more significant difference was also found for SBI learners compared with the learners of the control group.

Table 2. Results of SPANOVA for the acceptability judgment test (arriver).

\begin{tabular}{llll}
\hline \multicolumn{1}{c}{ df } & & F & \multicolumn{1}{c}{ Sig. } \\
\hline Test time & 1.69 & 15.14 & $.000^{*}$ \\
SBI & 2 & 13.67 & $.000^{*}$ \\
TBI & 2 & 12.56 & $.047^{*}$ \\
Time \& Exp. & 3.382 & 2.45 & $.050^{*}$ \\
\hline
\end{tabular}

Sur: Descriptive statistics of the acceptability judgment test scores for sur are shown in Table 3. Figure 6 illustrates the accuracy percentages of the test scores. The SBI group's scores improved greatly from pre-test to post-test 1. Whereas the TBI group showed a slight improvement from pre-test to post-test 1, the scores of the control group were not drastically improved.

Table 3. Descriptive statistics of the acceptability judgment test scores (sur).

\begin{tabular}{|c|c|c|c|c|c|c|c|c|c|}
\hline & \multicolumn{3}{|c|}{$\mathrm{SBI}(\mathrm{n}=15)$} & \multicolumn{3}{|c|}{ TBI $(n=16)$} & \multicolumn{3}{|c|}{ Control $(\mathrm{n}=18)$} \\
\hline & Mean & $\%$ & SD & Mean & $\%$ & SD & Mean & $\%$ & SD \\
\hline Pre-test & 9.20 & 58.63 & 1.98 & 9.38 & 62.11 & 1.94 & 10.03 & 69.70 & 2.03 \\
\hline Post-test 1 & 12.38 & 81.81 & 2.18 & 11.15 & 70.81 & 1.65 & 11.01 & 70.64 & 1.71 \\
\hline Post-test 2 & 12.74 & 85.01 & 1.79 & 11.14 & 70.78 & 1.71 & 11.31 & 72.61 & 1.65 \\
\hline
\end{tabular}

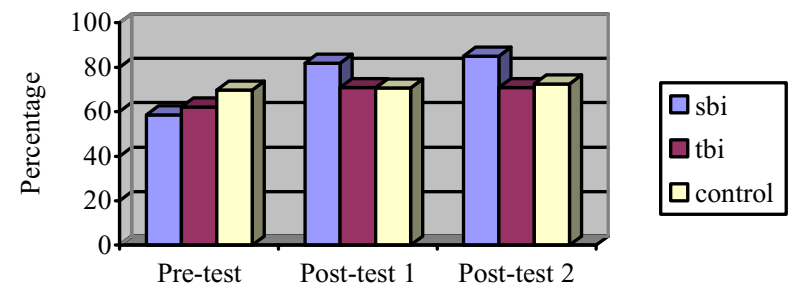

Figure 6. Accuracy percentages of the acceptability judgment test scores (sur).

The SPANOVA results are summarized in Table 4. The main effects for test time and our experimental techniques were significant ( $\mathrm{Sig}_{-} .000$ and $\mathrm{Sig}_{-} .000$, and .047 respectively) as was the interaction between test time and treatment (Sig $\left.{ }_{-} .010\right)$. Post hoc pair-wise 
comparisons revealed that on post-test 1, the SBI group scored significantly higher than the TBI and control groups. No significant differences were found between the scores of the TBI and control groups. Finally, on post-test 2, there were no significant differences among the three groups except for SBI learners.

Table 4. Results of SPANOVA for the acceptability judgment test (sur).

\begin{tabular}{lccc}
\hline & df & F & Sig. \\
\hline Test time & 2 & 9.409 & $.000^{*}$ \\
SBI & 2 & 4.513 & $.000^{*}$ \\
TBI & 2 & 3.233 & $.047^{*}$ \\
Time \& exp. & 4 & 9.546 & $.010^{*}$ \\
\hline
\end{tabular}

\subsection{Production test}

Arriver: Table 5 presents the descriptive statistics of the production test scores on arriver. Figure 7 shows the accuracy percentages of the test scores. The SBI unlike TBI group showed dramatic improvement from pre-test to post-test 1. Although TBI and control group exhibited constant improvement from test to test, it failed to reach the levels of the SBI group at the end of the study. The SPANOVA results, reported in Table 6 , indicate a significant main effect for test time ( Sig _ .000) and for SBI (Sig _.000) but not for TBI (Sig_.124). The interaction between test time and treatment reached significance (Sig. _. 01). Post hoc pair-wise comparisons revealed that on post-test 1, the control group's scores were significantly lower than those of SBI group and TBI group. There were no significant differences in the post-test 2 scores among except for SBI learners.

Table 5. Descriptive statistics of the production test scores (arriver).

\begin{tabular}{|c|c|c|c|c|c|c|c|c|c|}
\hline & \multicolumn{3}{|c|}{ SBI $(n=15)$} & \multicolumn{3}{|c|}{ TBI $(n=16)$} & \multicolumn{3}{|c|}{ Control $(n=18)$} \\
\hline & Mean & $\%$ & $\mathrm{SD}$ & Mean & $\%$ & SD & Mean & $\%$ & SD \\
\hline Pre- & 2.35 & 38.45 & .98 & 2.38 & 40.74 & .94 & 2.97 & 50.01 & 1.14 \\
\hline Post-test 1 & 5.35 & 88.14 & .84 & 4.15 & 71.18 & 1.06 & 3.96 & 68.71 & 1.07 \\
\hline Post-test 2 & 5.38 & 89.80 & 1.11 & 4.61 & 73.74 & 1.07 & 4.01 & 70.11 & 1.41 \\
\hline
\end{tabular}




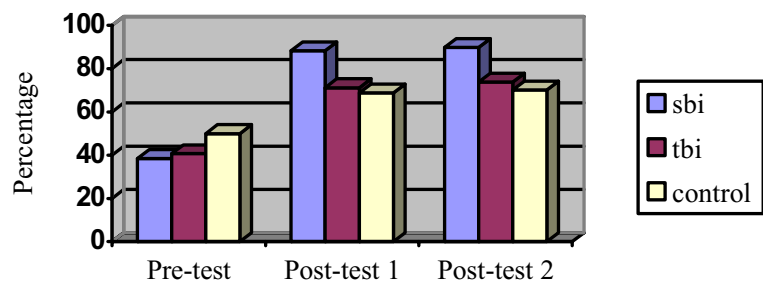

Figure 7. Accuracy percentages of the production test scores (arriver).

Table 6. Results of SPANOVA for the production test (arriver).

\begin{tabular}{llll}
\hline & df & F & Sig. \\
\hline Test time & 1.612 & 119.409 & $.000^{*}$ \\
SBI & 2 & 6.379 & $.000^{*}$ \\
TBI & 3.224 & 2.379 & .102 \\
Time \& exp. & 4 & 14.896 & $.010^{*}$ \\
& & & \\
\hline
\end{tabular}

Sur: Table 7 summarizes the descriptive statistics of the production test scores for sur. Figure 8 shows the accuracy percentages of the test scores. A glance at Figure 8 indicates that the SBI group scores improved strikingly from pre-test to post-test 1 (in comparison with the scores of TBI which slightly altered), reaching over $90 \%$ accuracy. Although the scores of the control group gradually improved from test to test, it did not reach the levels of the SBI learners.

Table 7. Descriptive statistics of the production test score (sur).

\begin{tabular}{|c|c|c|c|c|c|c|c|c|c|}
\hline & \multicolumn{3}{|c|}{$\operatorname{SBI}(n=15)$} & \multicolumn{3}{|c|}{ TBI $(n=16)$} & \multicolumn{3}{|c|}{ Control $(n=18)$} \\
\hline & Mean & $\%$ & SD & Mean & $\%$ & SD & Mean & $\%$ & SD \\
\hline Pre-test & 2.85 & 47.11 & 1.03 & 2.98 & 48.14 & .81 & 3.01 & 51.38 & 1.13 \\
\hline Post-test 1 & 4.89 & 88.14 & 1.43 & 4.01 & 72.41 & .83 & 3.41 & 60.18 & 1.10 \\
\hline Post-test 2 & 4.84 & 89.56 & 1.38 & 4.21 & 77.11 & 1.21 & 3.38 & 59.11 & 1.04 \\
\hline
\end{tabular}




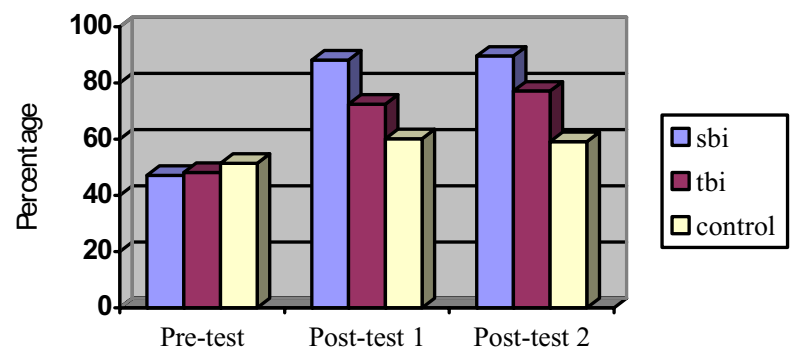

Figure 8. Accuracy percentages of the production test scores (sur).

The SPANOVA results, reported in Table 8, indicate a significant main effect for test time $\left(\mathrm{Sig}_{-} .01\right)$ and for SBI ( $\left.\mathrm{Sig}_{-} .001\right)$. There was a significant interaction between time and treatment $\left(\mathrm{Sig}{ }_{-} .01\right)$. The results of post hoc comparisons revealed that on post-test 1 , both the SBI and TBI groups' scores were higher than that of the control group although this superiority was not significant in the case of TBI learners.

Table 8. Results of SPANOVA for the production test (sur).

\begin{tabular}{lccl}
\hline & df & F & Sig. \\
\hline Test time & 2 & 75.939 & $.000^{*}$ \\
SBI & 2 & 5.423 & $.001^{*}$ \\
TBI & 2 & 1.506 & .231 \\
Time \& exp. & 4 & 14.896 & $.010^{*}$ \\
\hline
\end{tabular}

Overall, the results showed that generally the scores of the SBI and TBI groups on the post-tests were higher than those of the control group for the acceptability judgment test but not for the production test in which SBI learners outperformed significantly compared with learners of TBI and the control group. It should also be noted that the SBI and TBI groups' scores tended to be consistent on the first and the second posttest which may be considered as a sign of reliability of the proposed vocabulary instruction technique.

\section{Discussion}

It has been generally agreed upon that the first goal of vocabulary learning for beginner and intermediate learners is the mastery of approximately 3000 high-frequency words (Hazenburg and Hulstijn, 1996; Loewen and Ellis, 2004; Laufer, 1992, 1997; Nation, 1990) which enables learners to achieve 95\% comprehension of general texts (Nation, 
2001). As Nation (2001: 16) argues, '[t]he high-frequency words of the language are clearly so important that considerable time should be spent on them by teachers and learners'. As Nation (2001) argued, what is of crucial importance in designing a vocabulary component of language teaching is to make a balance between meaning-focused input, meaning-focused output, language-focused learning, and fluency development. In light of his argument, both ISBI and TBI can be considered as constituting only a portion of the necessary vocabulary instruction. It thus follows that the effectiveness of instruction needs to be viewed in a larger framework, taking into account how a given component is related to and utilized in other components of the instruction (De Carrico, 2001; Robinson, 1989). However, it can also be argued that in general, it is quite unusual for teachers to spend much time on teaching a single word and therefore 20 minutes of instruction may be more than is provided in most classroom contexts.

This study investigated the relative effectiveness of image-schema-based instruction on the acquisition of L2 polysemous words by Iranian intermediate learners of English. it was shown that image-schema-based instruction was as effective as translation-based instruction on acceptability judgment and more effective on production tests. Generally speaking, the results of this study provide some evidence that explicit instruction had positive effects on learners' more accurate use of L2 polysemous words. The results indicated that in most cases, schema-based instruction and translation-based instruction group outperformed the control group on both the acceptability judgment test and the production test.

Considering the obtained results that SBI was more effective than TBI in teaching sur than arriver, it is conceivable that the effectiveness of image-schema depended on (1) the word class, i.e. whether it is a verb or a preposition (Beaton, 1993; Morimoto and Loewen 2007) and (2) availability of L1 equivalents (Cho, 2002). In the case of sur, it could have been easier for learners to understand how various senses, including those in the metaphorical domain, are semantically related because of the image-schema which represented the spatial relationship between the two entities. In addition, since over can be associated with a number of Persian L1 equivalents (rooye, bar, be tarafe), learners might have been able to see its image-schema as a gestalt, which could have reduced their reliance to the L1.On the other hand, because of the lack of possible candidates for arriver in Persian other than residan, which leads to the relative strength of 'arriver=residan' equation, it is speculated that learners tended to see the semantics of arriver through that of residan regardless of the presentation of image-schema. Although image-schema seemed to be effective for learners' understanding of the use in the physical domain, it might have been difficult for learners to understand how the image-schema could be applied in metaphorical domains, such as 'Il a arrive' $a$ ' faire son examen'.

Pedagogical implications: Although the present study results were less than conclusive, image-schema-based instruction was found to be of benefit in the classroom. One of the options for teachers is to provide learners with ample example sentences containing the target word and ask them to discuss the core meaning and to draw its image-schema. After the completion of the task, the teacher would invite the whole class to discuss the core meaning by comparing the image-schemas drawn by each group. This kind of collaborative task is not only interesting for learners to take part in but can also 
involve deeper processing of the material than was done in the present study. In any case, it has to be born in mind that what is of crucial importance would be how teachers view the meaning potential of the target words, for it can greatly influence the presentation of the senses and explanations as to how various senses are semantically related to one another.

\section{REFERENCES}

Beitel, D.A., Gibbs, R.W.J. and Sanders, P. (1997). "The embodied approach to the polysemy of the spatial preposition on", in H. Cuyckens, H. and B. Zawada, B.(eds.), Polysemy in cognitive linguistics: Selected papers from the fifth international cognitive linguistics conference, Amsterdam, 1997; Amsterdam: John Benjamins, 241-60.

Bensoussan, M. and Laufer, B. (1984). "Lexical guessing in context in EFL reading comprehension", in Journal of Research in Reading 7: 15-32.

Bolinger, D. (1965). "The atomization of meaning", in Language, 41: 555-73.

Brugman, C.M. (1988). Story of over. Unpublished M.A. thesis, University of California, Berkeley. Reproduced by Indiana University Linguistics Club.

Cho, K. (2002). "A cognitive linguistic approach to the acquisition of English prepositions", in JACET Bulletin, 35: 63-78.

Craik, F.I.M. and Lockhart, R.S. (1972). "Levels of processing: A framework for memory research", in Journal of Verbal Learning and Verbal Behavior, 11: 671-84.

Csábi, S. (2004). "A cognitive linguistic view of polysemy in English and its implications for teaching", in M. Achard, M. and S. Niemeier, S., (eds.), editors, Cognitive linguistics, second language acquisition, and foreign language teaching, New York: Mouton de Gruyter, 241-60.

Curtis, M.E. (1987). "Vocabulary testing and instruction", in M.G. McKeown, M.G. and M.E. Curtis, M.E. (eds.), The nature of vocabulary acquisition, London: Lawrence Erlbaum Associates, 37-51.

DeCarrico, J.S. (2001). "Vocabulary learning and teaching", in M. Celce-Murcia, (ed.) M., Teaching English as a second of foreign language, third edition, Boston: Heinle \& Heinle, 285-99.

Dewell, R.B. (1994). "Over again: schema transformation in semantic analysis", in Cognitive Linguistics, 5: 351-80.

Ellis, N.C. and Beaton, A. (1993). "Psycholinguistic determinants of foreign language vocabulary learning", in Language Learning, 43(4): 559-617.

Gibbs, R.W.J. and Colston, H.L. (1995). "The cognitive psychological reality of image schemata and their transformations", in Cognitive Linguistics, 6: 347-78.

Goddard, C. (2002). "On and on: Verbal explications for a polysemic network", in Cognitive Linguistics, 13: 277-94.

Hatch, E. (1978). Second language acquisition. Rowley, Massachussetts: Newbury House.

— 1983: Psycholinguistics: A second language perspective. Rowley, MA: Newbury House.

Hazenburg, S. and Hulstijn, J. (1996). "Defining a minimal receptive second language vocabulary for non-native university students: An empirical investigation", in Applied Linguistics, 17: $145-63$.

Henriksen, B. (1999). "Three dimensions of vocabulary development", in Studies in Second Language Acquisition, 21: 303-17. 
1988: "Spatial expressions and the plasticity of meaning", in B. Rudzka-Ostyn, (ed.), Topics in cognitive linguistics. Amsterdam: John Benjamins, 271-298.

Howards, M. (1964). "How easy are "easy" words?", in Journal of Experimental Education, 32: 377-82.

Johnson, M. (1987). The body in the mind: The bodily basis of meaning, imagination and reason. Chicago: University of Chicago Press.

Kövecses, Z. and Szabó, P. (1996). "Idioms: A view from cognitive semantics", in Applied Linguistics, 17: 326-55.

Krashen, S. (1985). The input hypothesis: Issues and implications. New York: Longman.

Lakoff, G. (1987). Women, fire, and dangerous things: What categories reveal about the mind. Chicago: University of Chicago Press.

Lakoff, G. and Johnson, M. (1980). Metaphors we live by. Chicago: University of Chicago Press. Langacker, R.W. (1987). Foundations of cognitive grammar I: Theoretical prerequisites. Stanford, CA: Stanford University Press.

Laufer, B. (1992). "Reading in a foreign language: How does L2 lexical knowledge interact with the reader's general academic ability?", in Journal of Research in Reading, 15: 95-103.

1997: "The lexical plight in second language reading". Iin J. Coady, J. and T. Huckin, T. (eds.), Second language vocabulary acquisition, Cambridge: Cambridge University Press, 20-34.

Lennon, P. (1996). "Getting 'easy' verbs wrong at the advanced level”, in. International Review of Applied Linguistics, 34: 23-36.

Lindstromberg, S. (1996). "Prepositions: Meaning and method"., in ELT Journal, 50: 225-36.

Loewen, S. and Ellis, R. (2004). "The relationship between English vocabulary knowledge and the academic success of second language university students", in New Zealand Studies in Applied Linguistics, 10: 1-29.

Lyons, J. (1977). Semantics, Volume 2. Cambridge: Cambridge University Press.

Melka, F. (1997). "Receptive vs. productive aspects of vocabulary.", in N. Schmitt, N. and M. McCarthy, M., (eds), Vocabulary: Description, acquisition and pedagogy, Cambridge: Cambridge University Press, 84-102.

Morimoto, Sh. and Loewen, Sh. (2007). "A comparison of the effects of image-schema-based instruction and translation-based instruction on the acquisition of L2 words", in Language Teaching Research, 11(3): 347-372.

Nagy, W. (1997). "On the role of context in first- and second-language vocabulary learning", in N. Schmitt, N. and M. McCarthy, M. (eds.), Vocabulary: Description, acquisition and pedagogy, Cambridge: Cambridge University Press, 64-83.

Nation, I.S.P. (1990). Teaching and learning vocabulary. New York: Newbury House.

- (2001). Learning vocabulary in another language. Cambridge: Cambridge University Press.

Robinson, P. (1989). "A rich view of lexical competence", in ELT Journal, 43: 274-82.

Schmidt, R. (1990). "The role of consciousness in second language learning", in Applied Linguistics, 11: $129-58$.

Taylor, B. (1985). "The use of overgeneralization and transfer learning strategies by elementary and intermediate students in ESL", in Language Learning, 25: 73-108.

Taylor, J.R. (1988). "Contrasting prepositional categories: English and Italian”, in B. RudzkaOstyn, B. (ed.), Topics in cognitive linguistics, Amsterdam: John Benjamins, 299-326.

Tomasello, M. and Herron, C. (1989). "Feedback for language transfer errors: The Garden Path technique", in Studies in Second Language Acquisition, 11: 385-95.

Tyler, A. and Evans, V. (2001). "Reconsidering prepositional polysemy networks: The case of over", in. Language, 77: 724-65. 
-2004: "Applying cognitive linguistics to pedagogical grammar: The case of over", in M. Achard, M. and S. Niemeier, S. (eds.), Cognitive linguistics, second language acquisition, and foreign language teaching, New York: Mouton de Gruyter, 257-80.

Yamaoka, T. (1995). "A prototype analysis of learning of on by Japanese learners of English and the potentiality of prototype contrastive analysis (Part 1)", in Hyogo University of Teacher Education Journal, 15: 51-59. 